\title{
DIGESTÃO DE CARBOIDRATOS USANDO DIGESTIVOS ENZIMÁTICOS COMERCIAIS - UMA AULA PRÁTICA.
}

Maria Teresa Pedrosa Silva Clerici ${ }^{1}$, Roberval Serafim da Silva ${ }^{2}$, Armindo Antonio Alves $^{1}$

${ }^{1}$ UNIARARAS - Araras - SP; ${ }^{2}$ Químico Industrial

* alvesaa@uol.com.br

\section{Resumo:}

Este trabalho mostra uma aula prática na qual se estuda a digestão de carboidratos "in vitro" utilizando amido gelatinizado como substrato e dois medicamentos comerciais indicados para problemas digestórios, como fonte de amilase. As reações enzimáticas foram feitas no equipamento dissolutor a $37^{\circ} \mathrm{C}$, com agitação constante e usando meios que simulavam o pH do estômago e em seguida o $\mathrm{pH}$ do intestino delgado. Para avaliar a eficácia das enzimas pancreáticas nos digestivos, foi feita uma reação com amilase pancreática pura. Determinou-se a concentração de glicose no meio de reação 0, 30, 60, 90 e 120 min após o inicio da reação. Nossos resultados mostram que há diferenças entre a atividade amilase dos dois fármacos.

\section{Abstract:}

This work presents a practical class to study the "in vitro" carbohydrates digestion. We used gelatinized starch as substrate and two usual digestive medicines as the amylase source. The enzymatic reactions were made in the dissolutor equipment, temperature $37^{\circ} \mathrm{C}$, constant agitation, and buffers to simulate the stomach and small intestine $\mathrm{pH}$. To evaluate the pancreatic enzymes in the medicines, we made an amylase assay using a purified enzyme. The glucose concentration in the reaction middle was measured 0, 30, 60, 90 e 120 min after the starting reaction. These results show differences between the two medicines amylase activity. 


\section{Introdução}

Neste trabalho apresentamos uma aula prática de enzimologia utilizada por nós na disciplina de Biotecnologia nos cursos das instituições onde trabalhamos. Esta aula prática poderá ser utilizada em disciplinas de Bioquímica Básica, Enzimologia e Biotecnologia aplicada para o curso de Farmácia, para trabalhar conhecimentos teóricos de enzimologia, como atividade enzimática, $\mathrm{pH}$ ótimo e temperatura ótima de trabalho das enzimas, usando-se como solução enzimática um digestivo enzimático, que pode ser obtido em farmácias ou drogarias e como substrato amido gelatinizado. Pode também ser uma aula de integração da Biotecnologia com as disciplinas de Tecnologia Farmacêutica e Atenção farmacêutica, porque permite abordagens que vão desde o processo que deve ser utilizado para o encapsulamento de enzimas sensíveis a pH ácido (estômago), indicações terapêuticas dos digestivos, processos de extração e purificação de enzimas etc.

\section{Referencial Teórico}

O processo digestório inicia-se na boca, mas é no estômago e no intestino delgado que ele se completa e onde se dá a absorção da maior parte dos nutrientes [1]. Para os carboidratos, o processo se inicia na boca, mas ocorre em sua maior parte no intestino, como mostramos no esquema apresentado na Figura 1, usando como exemplo o amido gelatinizado. O amido gelatinizado foi obtido cozinhando-se o amido cru durante trinta minutos, de forma a se obter uma estrutura pronta para ser digerida pelas enzimas do sistema digestório.

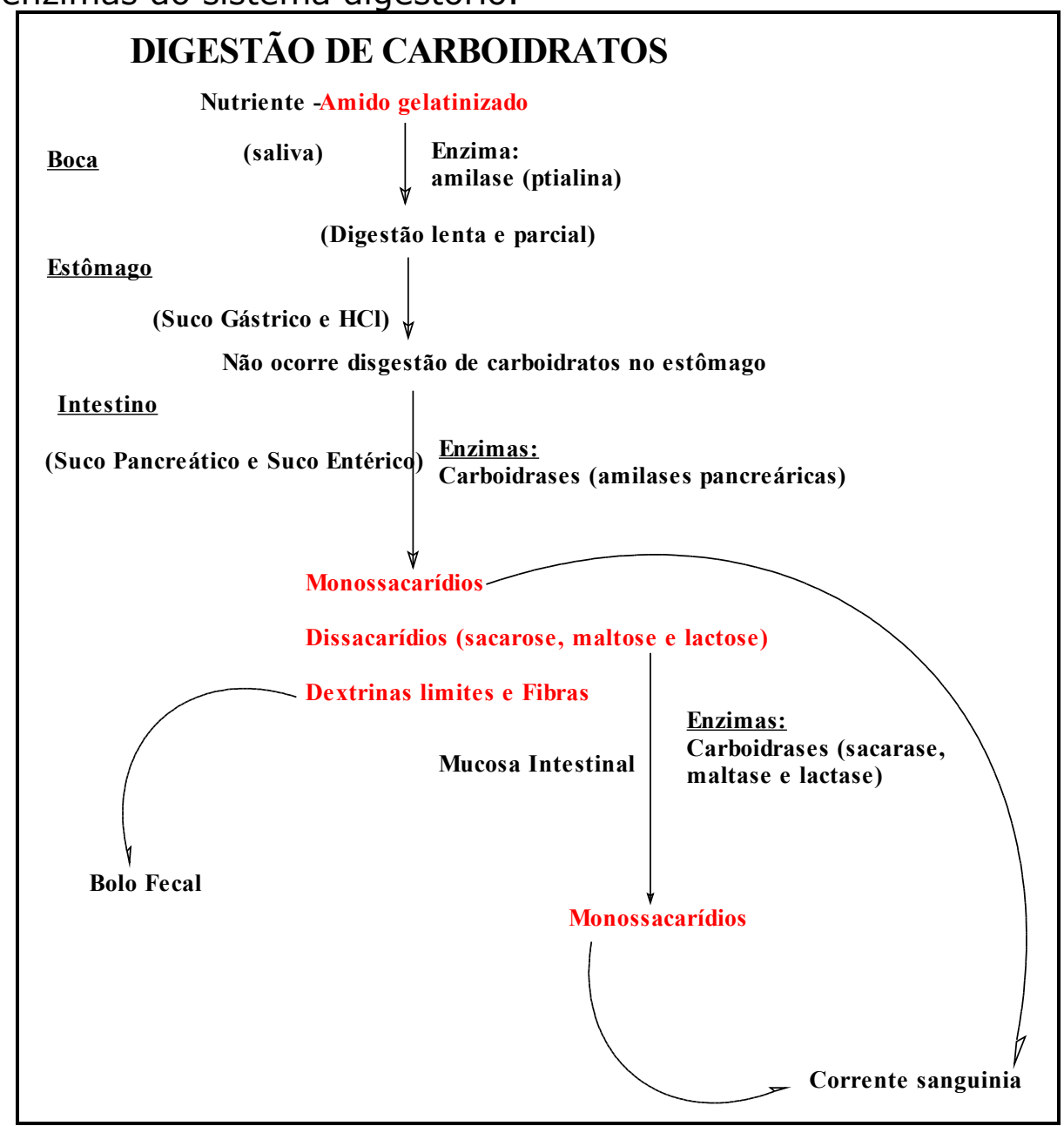

Figura 1. Digestão de Carboidratos in vivo [1.2].

No processo de tratamento de algumas doenças como pancreatite crônica, insuficiência pancreática e fibrose cística há necessidade de se administrar 
medicamentos digestivos contendo enzimas. Estes medicamentos geralmente são preparações de extrato pancreático contendo amilase, lipase e protease [3].

Os digestivos enzimáticos, contendo amilase, lipase e protease, normalmente são obtidos de pâncreas de porco, cujo padrão enzimático é semelhante ao da secreção pancreática fisiológica do homem. Estes medicamentos facilitam a digestão e auxiliam a função exócrina do pâncreas e são utilizados quando esta glândula está acometida por uma doença ou uma insuficiência.

Dentre os medicamentos presentes no mercado, alguns são formados por cápsulas que contêm microcomprimidos de panctreatina com revestimento entérico. Após a dissolução da cápsula, os microcomprimidos se misturam aos alimentos no meio ácido do estômago. Durante o trânsito gástrico, o revestimento entérico dos microcomprimidos impede a inativação das enzimas pancreáticas. Ao entrar no duodeno, o revestimento entérico se dissolve com rapidez e os microcomprimidos liberam as enzimas pancreáticas. Assim, estas formulações permitem a administração oral do medicamento.

\section{Objetivos da Aula}

Entender a digestão de carboidratos através da simulação in vitro, usando o dissolutor, enzimas digestivas e substrato específico, como por exemplo, o amido gelatinizado.

Avaliar os efeitos de digestivos enzimáticos na digestão de carboidratos em meios que simulam as condições de temperatura, agitação e pH do estômago e do intestino delgado.

Aprender a utilizar um método enzimático de determinação de glicose.

Aprender os procedimentos estatísticos para análise de resultados obtidos em laboratório

\section{MATERIAIS}

a) Reagentes:

Pasta de amido gelatinizado em autoclave por 30 minutos, contendo $10 \mathrm{~g}$ de amido peso/volume em água para $100 \mathrm{~mL}$.

Dois medicamentos contendo enzimas digestivas, foram indicados pelas letras $A$ e $B$, para evitar divulgação de marcas.

Medicamento A - 218,20 a 282,40 mg de pancreatina por cápsula (lipase, $25.000 \mathrm{U}$; amilase $22.500 \mathrm{U}$; protease $1.250 \mathrm{U}$ ).

Medicamento B - $40 \mathrm{mg}$ de pancreatina por cápsula.

Solução de $\mathrm{HCl} 0,01$ mols. $L^{-1}$.

Bicarbonato de sódio em pó.

Amilase pancreática Prozyn

KIT GLICOSE-Método enzimático - CATNo 02200 da LABORLAB

\section{b) Equipamentos}

Para mimetizarmos in vitro o processo digestório, utilizamos um equipamento de uso comum em laboratórios de controle de qualidade de medicamentos, 0 dissolutor, este equipamento possui cubas termostatizadas e um sistema de agitação com velocidade controlada, sendo utilizado para se estudar o tempo que uma determinada formulação farmacêutica leva para se desintegrar (Figura 2).

$\mathrm{O}$ dissolutor foi mantido à temperatura de $37^{\circ} \mathrm{C}$, e inicialmente foi adicionada uma solução de $\mathrm{HCL} 0,01$ mols/L, para ter um $\mathrm{pH}=2,0$. 


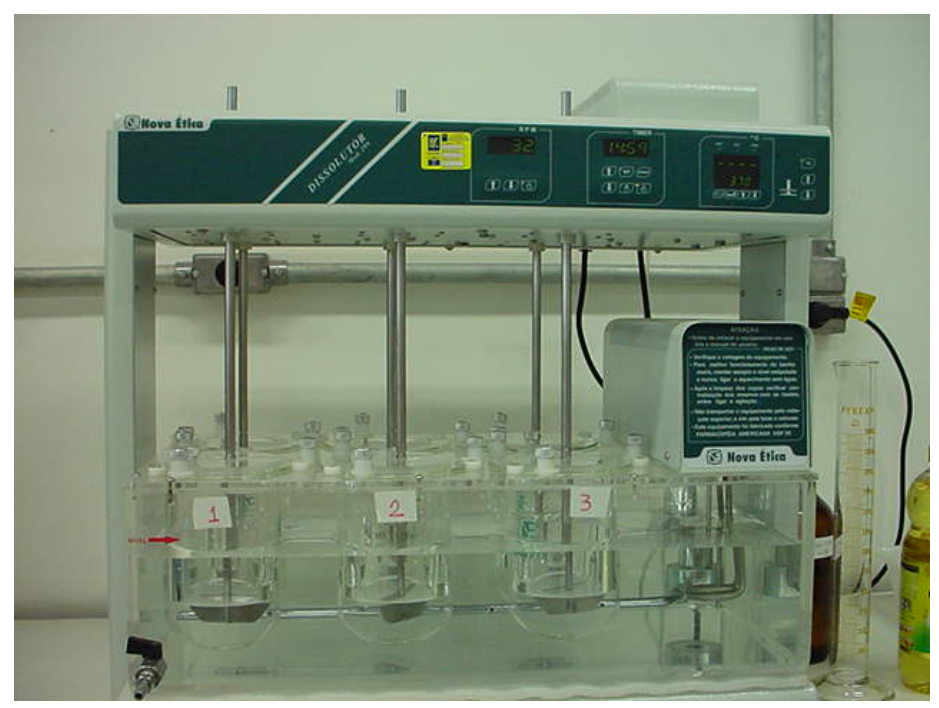

Figura. 2. Fotografia do dissolutor utilizado para realização do experimento.

Banho maria a $37^{\circ} \mathrm{C}$.

Espectofotômetro a $505 \mathrm{~nm}$.

c) Vidrarias

Pipetas volumétricas de 1,2 e $3 \mathrm{~mL}$.

Micropipetas de 25 $\square \mathrm{L}$.

Tubos de ensaio de $20 \mathrm{~mL}$.

d) Preparo do amido

$\mathrm{O}$ amido de milho foi dissolvido em água $(10 \mathrm{~g} / 100 \mathrm{~mL})$, gelatinizado em autoclave a $121^{\circ} \mathrm{C}, 1 \mathrm{Atm}$, por 30 minutos (cozido até desintegração dos grânulos). Após resfriamento em água corrente, corrigiu-se o volume para $100 \mathrm{~mL}$, obtendo-se assim uma solução de amido gelatinizado $10 \%$.

\section{MÉTODOS:}

a) Digestão do amido

As cubas do dissolutor foram preparadas conforme o esquema, apresentado na Figura 3, que também descreve os procedimentos usados durante a mimetização do processo digestório dos amidos. 


\begin{tabular}{|c|c|c|c|}
\hline $\begin{array}{l}\text { Cuba } 1 \\
-0,5 \mathrm{~L} \mathrm{HCl} 0,01 \mathrm{~mol} \cdot \mathrm{L}^{-1} \\
-30 \mathrm{~g} \text { de amido } \\
\text { - amilase pancreática } \\
(20 \mathrm{mg})\end{array}$ & $\begin{array}{l}\text { Cuba } 2 \\
-0,5 \mathrm{~L} \mathrm{HCl} 0,01 \mathrm{~mol} . \mathrm{L}^{-1} \\
-30 \mathrm{~g} \text { de amido }\end{array}$ & 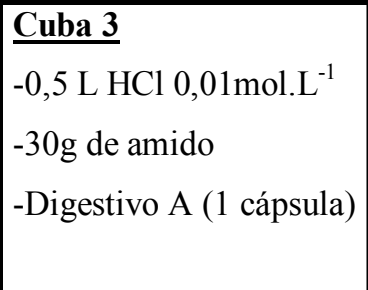 & $\begin{array}{l}\text { Cuba } 4 \\
-0,5 \mathrm{~L} \mathrm{HCl} 0,01 \mathrm{~mol}^{-\mathrm{L}^{-1}} \\
-30 \mathrm{~g} \text { de amido } \\
\text {-Digestivo B (1 cápsula) }\end{array}$ \\
\hline
\end{tabular}

Manter por 1 hora, em $\mathrm{pH}=2$, à $37^{\circ} \mathrm{C}$

com agitação. Após, neutralizar e ajustar

o pH para 8, usando $\mathrm{Na}_{2} \mathrm{HCO}_{3}$ em pó.

\begin{tabular}{|c|c|c|c|}
\hline$\frac{\text { Cuba 1 }}{-\mathrm{pH}=8}$ & $\begin{array}{l}\frac{\text { Cuba 2 }}{-\mathrm{pH}=8} \\
\text { - amilase pancreática (20 } \\
\mathrm{mg})\end{array}$ & $\frac{\text { Cuba } 3}{-\mathrm{pH}=8}$ & $\frac{\text { Cuba 4 }}{-\mathrm{pH}=8}$ \\
\hline & & Manter por 1hora & \\
\hline
\end{tabular}

Final do Processo

Figura 3. Esquema da processo digestório dos amidos no dissolutor.

Retiraram-se alíquotas para determinar glicose nos seguintes tempos:

Tempo 0: inicio do processo (mimetizando a chegada ao estômago)

Tempo $30 \mathrm{~min}$ :

Tempo 60min (tempo zero após neutralização)

Tempo 90 min

Tempo 120 minutos: final do processo

\section{Dosagem da glicose}

\section{Composição do KIT:}

1. Reativo Padrão CAT no. 02201 - Solução de glicose a 100mg/dL

2. Reativo Enzimático CAT no. 02202:

- Glicose Oxidase $\geq 1 \mathrm{KU} / \mathrm{mL}$

- Peroxidase $\geq 0,15 \mathrm{KU} / \mathrm{mL}$

3. Reativo de Cor 1: CAT. No. 02203

- 4-aminofenazona $0,025 \mathrm{~mol} / \mathrm{L}$

- Tampão Tris $0,92 \mathrm{~mol} / \mathrm{L}$

4. Reativo de Cor 2: CAT. No. 02204

- Fenol 0,055 mol/L

Preparo do Reativo de trabalho:

Adicionar em um balão volumétrico de $250 \mathrm{~mL}, 12,5 \mathrm{~mL}$ do reativo de cor $\mathbf{1}$, mais $225 \mathrm{~mL}$ de água destilada, $12,5 \mathrm{~mL}$ do reativo de cor 2 e $0,75 \mathrm{~mL}$ do reativo enzimático. 
Reações:

Glicose $+\mathrm{O}_{2}+\mathrm{H}_{2} \mathrm{O} \stackrel{\mathrm{GOD}}{\longrightarrow} \mathrm{H}_{2} \mathrm{O}_{2}+$ Ácido Glucorônico

$4 \mathrm{H}_{2} \mathrm{O}_{2}+$ 4aminoantipirina + fenol $\stackrel{\mathrm{POD}}{\longrightarrow} 4 \mathrm{H}_{2} \mathrm{O}+$ antipirilquininomina

A glicose presente na amostra sofre ação da enzima glicose oxidase (GOD) e o peróxido de hidrogênio produzido, reage com os reativos de cor, formando um complexo colorido que absorve a $505 \mathrm{~nm}$. Esta última reação é catalisada por uma peroxidase.

Para se proceder às medidas de concentração de glicose montou-se a bateria de tubos descrita na Tabela 1 . As determinações foram feitas em duplicata e incubadas a $37^{\circ} \mathrm{C}$ por 15 min, resfriadas em água corrente e lidas em espectrofotômetro a 505 $\mathrm{nm}$.

Tabela 1. Procedimento para dosagem da glicose.

\begin{tabular}{llll}
\hline Tubos & Reativo de Trabalho & Padrão & Amostras \\
\hline Branco & $3,0 \mathrm{~mL}$ & 0,00 & 0,00 \\
Cuba 1 & $3,0 \mathrm{~mL}$ & 0,00 & $1,0 \mathrm{~mL}$ \\
Cuba 2 & $3,0 \mathrm{~mL}$ & 0,00 & $1,0 \mathrm{~mL}$ \\
Cuba 3 (A) & $3,0 \mathrm{~mL}$ & 0,00 & $1,0 \mathrm{~mL}$ \\
Cuba 4 (B) & $3,0 \mathrm{~mL}$ & 0,00 & $1,0 \mathrm{~mL}$ \\
Padrão & $3,0 \mathrm{~mL}$ & $25 \mu \mathrm{L}$ & 0,00 \\
\hline
\end{tabular}

\section{RESULTADOS E DISCUSSÃO}

Após a análise, pedimos aos alunos que elaborassem uma tabela com todos os valores, como a análise foi feita duas vezes, para cada uma há dois valores. Os resultados de um dos grupos estão apresentados na Tabela 2.

Tabela 2. Resultados da ação enzimática sobre o amido pré-gelatinizado durante a digestão "in vitro" no dissolutor.

\begin{tabular}{ccccc}
\hline \multicolumn{5}{c}{ Glicose $(\mathbf{m g} / \mathbf{d L})$} \\
\hline Tempo (min) & Cuba 1 & Cuba 2 & Cuba 3 & Cuba 4 \\
\hline 0 & 1,01 & 2,68 & 2,68 & 2,68 \\
& 1,00 & 2,66 & 2,67 & 2,69 \\
30 & 1,01 & 3,69 & 25,84 & 11,74 \\
& 1,00 & 3,65 & 25,80 & 12,75 \\
60 & 0,67 & 7,20 & 37,58 & 14,35 \\
& 0,67 & 7,00 & 37,50 & 14,45 \\
90 & 0,67 & 11,41 & 41,61 & 15,24 \\
& 0,67 & 11,39 & 43,62 & 15,44 \\
120 & 0,67 & 15,44 & 47,99 & 18,46 \\
& 0,67 & 16,08 & 46,98 & 18,12 \\
\hline
\end{tabular}

$\mathrm{Na}$ Tabela 3, mostramos a análise estatística dos resultados com a média, o desvio padrão e o coeficiente de variação.

O coeficiente de variação (CV) dá uma idéia da precisão de um experimento, e quando menor que $10 \%$ a indicativo que os dados obtidos são bons [4]. 
Tabela 3. Resultados da análise estatística dos valores de glicose obtidos no experimento: média, desvio padrão e coeficiente de variação (CV).

\begin{tabular}{|c|c|c|c|c|c|c|c|c|}
\hline \multirow{3}{*}{$\begin{array}{l}\text { Tempo } \\
\text { (min) }\end{array}$} & \multicolumn{8}{|c|}{ Glicose (mg/dL) } \\
\hline & Cuba 1* & CV & Cuba 2* & CV & Cuba 3* & CV & Cuba 4* & CV \\
\hline & & $(\%)$ & & $(\%)$ & & $(\%)$ & & $(\%)$ \\
\hline 0 & $1,005 \pm 0,007$ & 0,70 & $2,67 \pm 0,014$ & 0,53 & $2,68 \pm 0,007$ & 0,26 & $2,68 \pm 0,007$ & 0,26 \\
\hline 30 & $1,005 \pm 0,007$ & 0,70 & $3,67 \pm 0,028$ & 0,77 & $25,82 \pm 0,028$ & 0,11 & $12,25 \pm 0,714$ & 5,83 \\
\hline 60 & $0,67 \pm 0,000$ & 0,00 & $7,10 \pm 0,141$ & 1,99 & $37,54 \pm 0,057$ & 0,15 & $14,4 \pm 0,071$ & 0,49 \\
\hline 90 & $0,67 \pm 0,000$ & 0,00 & $11,40 \pm 0,014$ & 0,12 & $42,61 \pm 1,421$ & 3,34 & $15,34 \pm 0,141$ & 0,92 \\
\hline 120 & $0,67 \pm 0,000$ & 0,00 & $15,67 \pm 0,453$ & 2,87 & $47,49 \pm 0,714$ & 1,50 & $18,29+0,240$ & 1,31 \\
\hline
\end{tabular}

Na Tabela 4, mostramos o comportamento da concentração de glicose ao longo do tempo de reação e as diferenças estatísticas entre os dados obtidos nas coletas, analisados pelo teste de Tukey, ao nível de $5 \%$ de probabilidade [5]. Este teste é utilizado quando se deseja comparar todo e qualquer contraste entre duas médias de tratamentos [4], neste caso foi feito com o objetivo de verificar se houve diferença significativa entre os valores médios de glicose durante os tempos usados no

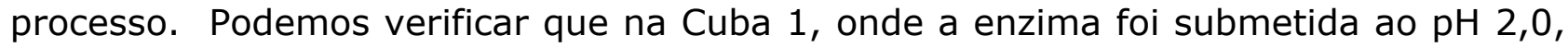
a concentração de glicose praticamente se manteve constante. A concentração de glicose encontrada é contaminação da amostra pela degradação espontânea do amido, porque havia glicose nas amostras de amido antes do experimento (dados não mostrados). A diferença observada na Cuba 1 ao longo do experimento é muito pequena quando comparada com o que ocorreu nas outras Cubas, conforme se pode observar no gráfico da Figura 4, indicando que não houve atividade enzimática. Nas Cubas 2, 3 e 4, houve aumento na concentração de glicose em função do tempo de reação, indicando uma ação enzimática efetiva.

Tabela 4. Resultados do teste de Tukey dos valores de glicose obtidos no experimento*.

\begin{tabular}{lllll}
\hline & \multicolumn{4}{c}{ Glicose $(\mathbf{m g} / \mathbf{d L})$} \\
Tempo (min) & Cuba 1* & Cuba 2* & Cuba 3* & Cuba 4* \\
\hline 0 & $1,005 \mathrm{a}$ & $2,67 \mathrm{a}$ & $2,68 \mathrm{a}$ & $2,68 \mathrm{a}$ \\
30 & $1,005 \mathrm{a}$ & $3,67 \mathrm{~b}$ & $25,82 \mathrm{~b}$ & $12,25 \mathrm{~b}$ \\
60 & $0,67 \mathrm{~b}$ & $7,10 \mathrm{C}$ & $37,54 \mathrm{C}$ & $14,4 \mathrm{C}$ \\
90 & $0,67 \mathrm{~b}$ & $11,40 \mathrm{~d}$ & $42,61 \mathrm{~d}$ & $15,34 \mathrm{C}$ \\
120 & $0,67 \mathrm{~b}$ & $15,67 \mathrm{e}$ & $47,49 \mathrm{e}$ & $18,29 \mathrm{~d}$ \\
\hline *As médias seguidas da mesma letra na vertical, não diferem estatisticamente entre si pelo teste de
\end{tabular}

Tukey a $5 \%$ de probabilidade.

As diferenças de comportamento das curvas das curvas 2, 3 e 4, apresentadas no gráfico da Figura 4 estão relacionadas com a quantidade de enzima amilase pancreática adicionadas, $20 \mathrm{mg}$ de enzima pura na Cuba 2, $218 \mathrm{mg}$ (1 cápsula de A) na Cuba 3 e 40 mg (1 cápsula de B) na Cuba 4. Mesmo levando em consideração que as preparações farmacêuticas A e B não continham só amilases nossos dados indicam que o fármaco $A$ apresentou maior atividade da enzima amilase.

Figura 4. Resultados da ação enzimática sobre o amido gelatinizado (10\%) durante a digestão in vitro no dissolutor. Na Cuba 1 e 2 houve adição de amilase pancreática (20 mg/mL) e na Cuba 3 e 4 os digestivos A e B. 
Esta aula prática se mostrou adequada para a discussão sobre o processo digestório dos amidos. Foram ainda discutidos coleta de dados, análise estatística e apresentação e interpretação de dados. A comparação do desempenho das duas preparações farmacêuticas permitiu discutir que a eficiência de medicamentos contendo enzimas deve ser baseada na sua atividade enzimática e não na massa do medicamento, $O$ medicamento $B$, apresenta na bula a quantidade em gramas da enzima e não sua atividade enzimática e essas duas grandezas não se comportam obrigatoriamente da mesma maneira, por isso é recomendável que as bulas descrevam a atividade enzimática de cada enzima que contém.

\section{Referências bibliográficas}

[1] SGARBIERI, V.C. Alimentação e Nutrição: fator de saúde e desenvolvimento. Ed. Unicamp. 1987.387p

[2] YOKAICHIYA, D.K. \& GALEMBEK, E. Nutrição. In: GALEMBEK, E \& TORRES, B.B. Bioquímica: softwares educacionais., ISBN85-901261-1-0.

[3] KOROKOLVAS, A. \& FRANÇA, F.F.A.C. Dicionário Terapêutico Guanabara. Ed. Guanabara Koogan, ed. 2003/2004.

[4] PIMENTEL GOMES, F. Curso de Estatística Experimental. 10ed. São Paulo. Nobel. $1982,430 \mathrm{p}$.

[5] Statistica 5.0 for Windows. StatSoft, Inc. Tulsa, OK, USA, 1995. 